Corrigendum

\title{
Corrigendum to "Ferritin as a Risk Factor for Glucose Intolerance amongst Men and Women Originating from the Indian Subcontinent"
}

\author{
Jeetesh V. Patel, ${ }^{1,2}$ Paramjit S. Gill, ${ }^{3}$ Julia Chackathayil, ${ }^{3}$ Elif S. Agaoglu, ${ }^{2}$ Zosia Bredow, ${ }^{2}$ \\ Rebecca Mirrielees, ${ }^{2}$ Paul Flinders, ${ }^{2}$ and Elizabeth A. Hughes ${ }^{1}$ \\ ${ }^{1}$ University of Birmingham Centre for Cardiovascular Sciences, Sandwell and West Birmingham Hospitals NHS Trust, \\ West Midlands B18 7QH, UK \\ ${ }^{2}$ Medical School, University of Nottingham, Nottingham NG7 2UH, UK \\ ${ }^{3}$ Primary Care Clinical Sciences, University of Birmingham, West Midlands B15 2TT, UK \\ Correspondence should be addressed to Zosia Bredow; mzyzfb@nottingham.ac.uk \\ Received 7 March 2016; Accepted 20 June 2016 \\ Copyright (C) 2016 Jeetesh V. Patel et al. This is an open access article distributed under the Creative Commons Attribution License, \\ which permits unrestricted use, distribution, and reproduction in any medium, provided the original work is properly cited.
}

In the article titled "Ferritin as a Risk Factor for Glucose Intolerance amongst Men and Women Originating from the Indian Subcontinent" [1], the order of the authors is incorrect. The correct order of authors is shown above.

\section{References}

[1] E. A. Hughes, J. V. Patel, Z. Bredow et al., "Ferritin as a risk factor for glucose intolerance amongst men and women originating from the Indian subcontinent," International Journal of Endocrinology, vol. 2015, Article ID 924387, 6 pages, 2015. 


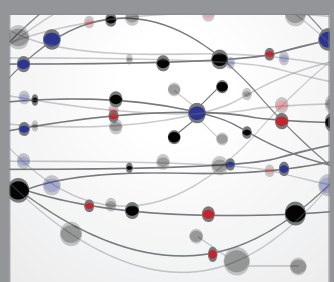

The Scientific World Journal
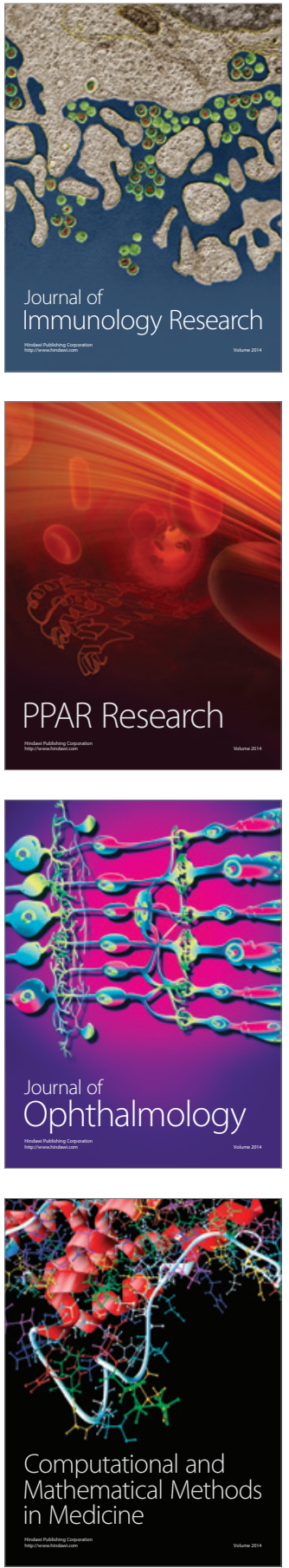

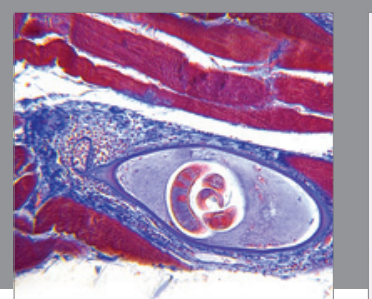

Gastroenterology Research and Practice

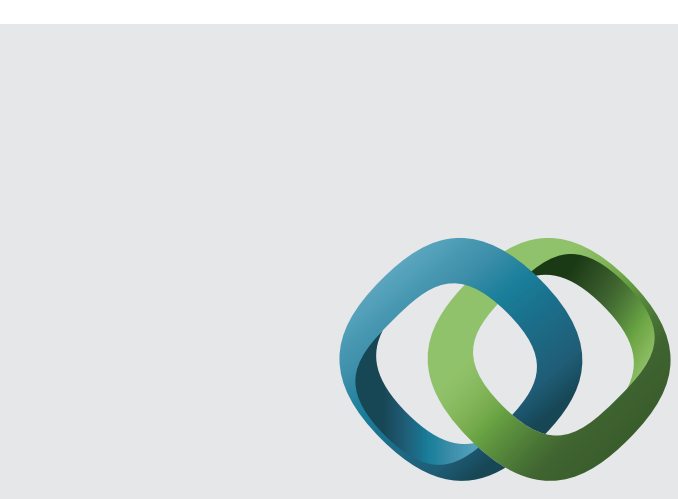

\section{Hindawi}

Submit your manuscripts at

http://www.hindawi.com
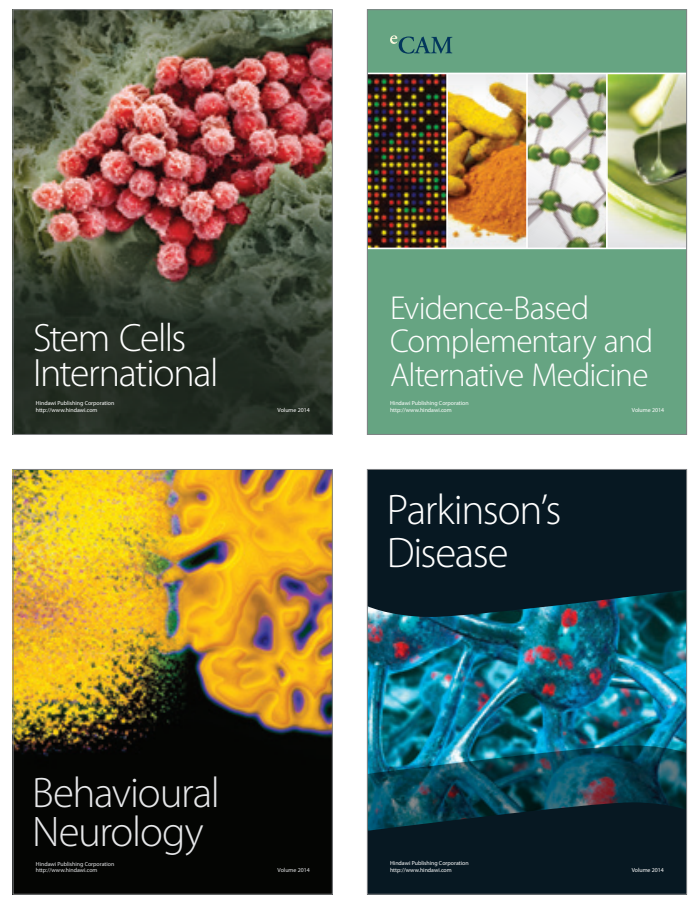
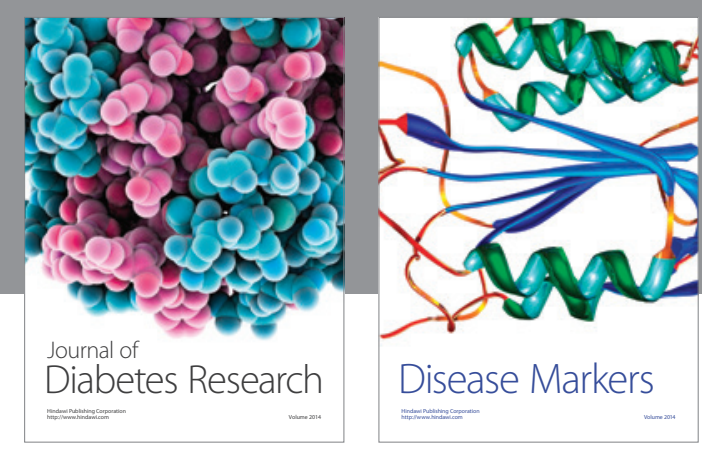

Disease Markers
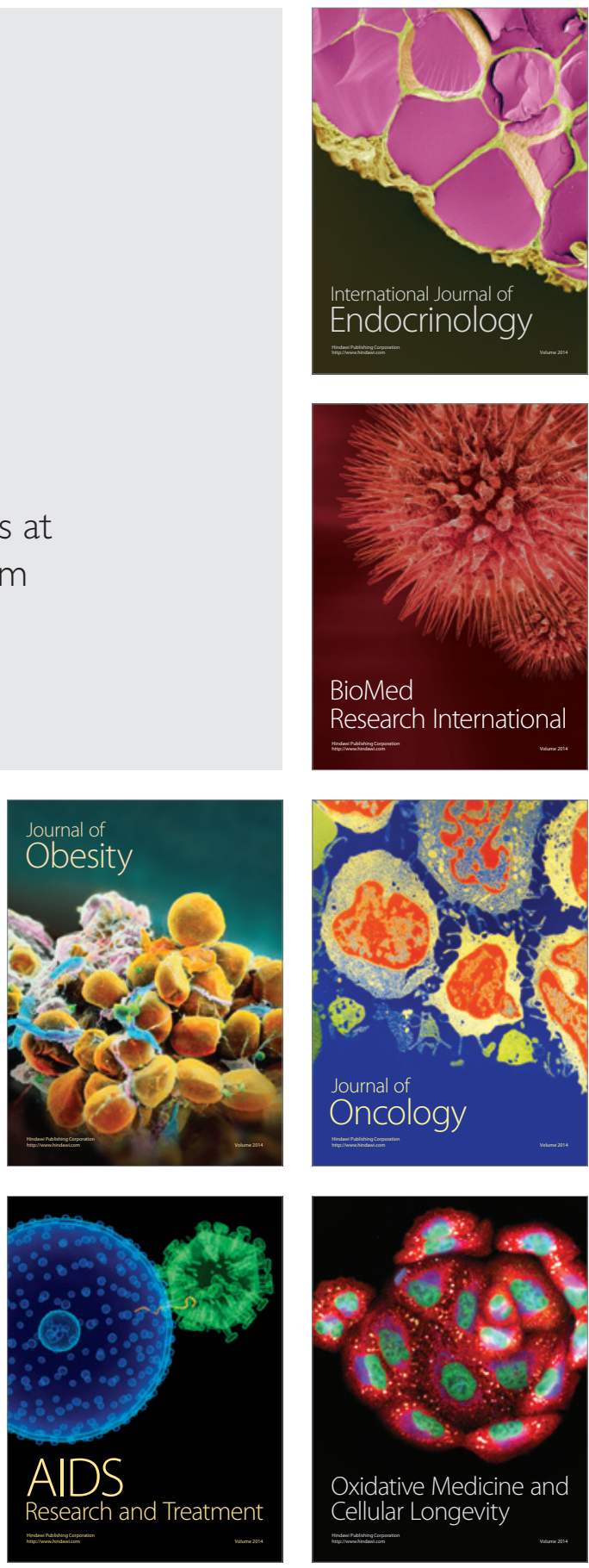